\title{
Importance of work-life balance among German medical students who wish to become gynecologists
}

\author{
Richard Kasch $\cdot$ L. Stollhof $\cdot$ A. P. Schulz $\cdot$ \\ S. Froehlich $\cdot$ H. Merk $\cdot$ J. Kasch
}

Received: 30 August 2014/Accepted: 22 October 2014/Published online: 8 November 2014

(C) Springer-Verlag Berlin Heidelberg 2014

\section{Dear Editor,}

Work-life balance is a crucial upcoming issue, not only for working physicians. Our future colleagues from generation Y, who are born after 1981, are known to attach much more importance to having good working conditions and meaningful lives outside work.

The well-conducted review of Hancke et al. [1], presenting a national survey of gynecologists recently published in Arch Gynecol Obstet, provided sufficient evidence to underline the importance of work-life balance. Up to $3 / 4$ of the gynecologists in this survey state that work life and private life are equally important to them. The results of this survey are startling, as only $50 \%$ of gynecologists are actually satisfied with their work-life balance.

The Committee of Medical Education (CME) of the DGOU also addressed the issue of work-life balance and conducted an online survey among medical students to ask their opinion on this topic in 2012. The questionnaire used in this national survey consists of approximately $160 \mathrm{items}$, and was completed by 465 German medical students from all 36 medical faculties who stated that they aspired to become gynecologists. Most questions were answered using a fivepoint Likert scale. This survey and the study of Hancke et al. [1] provide important insights regarding the importance of work-life balance for gynecologists and medical students.

This comment refers to the article available at doi:10.1007/s00404013-2949-y and an author's reply to this comment is available at doi:10.1007/s00404-014-3530-z.

R. Kasch $(\bowtie) \cdot$ L. Stollhof · A. P. Schulz · S. Froehlich · H. Merk - J. Kasch

Clinic and Outpatient Clinic for Orthopedics and Orthopedic Surgery, University Medicine Greifswald, Greifswald, Germany e-mail: kaschr@uni-greifswald.de
In our survey, the group of future gynecologists consisted of 98 preclinical, 282 clinical, and 85 last-year (Praktisches Jahr, PJ) students. A total of $96 \%$ of the students wishing to become gynecologists were born after 1980 and hence belonged to Generation Y. There was a strong predominance of female students with only 32 men $(6.9 \%)$ intending to specialize in gynecology [2, 3]. In analyzing this subgroup, we found the impact of work-life balance to be the \#1 topic for choosing job choice/ employer and being satisfied with the job as a gynecologist (mean 4.63, SD 0.63).At the same time, the expectation to actually have a good work-life balance on the job was lowest among students wishing to become gynecologists and it was lower in more advanced students with a significant group difference (mean 1.68, SD 1.15, $p=0.036$ ). We found this to be alarming as the importance of worklife balance contrasts sharply with the expectation that this wish will not come true. Hospitals wishing to attract skilled young physicians need to offer work environments allowing them to reconcile work with their ideas of living.

Conflict of interest Richard Kasch declares no conflict of interest.

\section{References}

1. Hancke K, Igl W, Toth B, Buhren A, Ditsch N, Kreienberg R (2014) Work-life balance of German gynecologists: a web-based survey on satisfaction with work and private life. Arch Gynecol Obstet 289(1):123-129

2. van Tongeren-Alers $M$, van Esch M, Verdonk P, Johansson E, Hamberg K, Lagro-Janssen T (2011) Are new medical students' specialty preferences gendered? Related motivational factors at a Dutch medical school. Teach Learn Med 23(3):263-268

3. Gedrose B, Wonneberger C, Junger J, Robra BP, Schmidt A, Stosch C et al (2012) Do female medical graduates have different views on professional work and workload compared to their male colleagues? Results of a multicenter postal survey in Germany. Dtsch Med Wochenschr 137(23):1242-1247 